\title{
FAKE NEWS EM TEMPOS DE COVID-19: DISCURSOS DE ÓDIO NAS REDES SOCIAIS COMO RESSONÂNCIA DA DESINFORMAÇÃO
}

\author{
Cleyton Williams Golveia da Silva Brandão ${ }^{\mathrm{i}}$ \\ Diego Aric Cerqueira Souza e Cruz ${ }^{i i}$ \\ Telma Brito Rocha ${ }^{\text {iii }}$
}

\begin{abstract}
Resumo: As redes sociais possibilitaram alterações nos processos comunicacionais, construção e compartilhamento de informações. Partindo das interações nessas redes, o presente texto analisa as fake news em tempos de pandemia no Brasil, assim como o processo de desinformação e os discursos de ódio, tomando como exemplo a discussão da medicação (hidroxi)cloriquina no tratamento de pacientes infectados pela COVID-19. Buscou-se investigar e apontar perspectivas relativas ao negacionismo científico, o uso estratégico da medicação como manipulação e jogos de interesses do governo atual nos conhecimentos difundidos sobre o medicamento, e, por fim, propor alternativas de caráter educativo para prevenir essas fake news em âmbito brasileiro no contexto da pandemia.
\end{abstract}

Palavras-Chave: Fake News; COVID-19; Discursos de Ódio; Desinformação.

\section{FAKE NEWS IN COVID-19 TIMES: HATE SPEECH ON SOCIAL MEDIA AS A RESONANCE OF DISINFORMATION}

\begin{abstract}
Social networks enabled changes in communication processes, construction and information sharing. Based on the interactions in these networks, this text analyzes the incidence of fake news in times of pandemic in Brazil, as well as the disinformation process and hate speech, taking as an example the discussion of (hydroxy) chloriquine medication in the treatment of infected patients by COVID-19. We sought to investigate and point out perspectives related to scientific denialism, the strategic use of medication as manipulation and games of interests of the current government in the knowledge disseminated about the medicine, and, finally, to propose educational alternatives to prevent these fake news in scope in the context of the pandemic.
\end{abstract}

Key words: Fake News; COVID-19; Hate speeches; Disinformation.

\section{INTRODUÇÃO}

A sociedade civil tem vivenciado e enfrentado um momento crítico de saúde pública, que afeta vários ordenamentos sociais: a Pandemia do COVID-19, ou comumente intitulada de novo Coronavírus. A síndrome é causada por uma doença que ataca o sistema respiratório. A denominação dela é determinada como síndrome respiratória aguda grave 2 (SARS - CoV2). A Organização Mundial de Saúde (OMS) está trabalhando em estreita colaboração com especialistas globais, governos e parceiros para expandir rapidamente o conhecimento 
científico sobre esse novo vírus, rastrear sua disseminação, virulência e aconselhar países, indivíduos sobre medidas para proteger a saúde e impedir a propagação do surto.

Em 30 de janeiro de 2020, o órgão decretou emergência de Saúde Pública, com caráter nocivo para as nações mundiais. O alerta deflagrado é caracterizado como de alto nível, conforme está descrito no Regulamento Sanitário Internacional, sendo a COVID-19 posicionada como uma Pandemia de ressonância perigosa ao desenvolvimento humano e de Saúde Pública Internacional.

O Ministério da Saúde do Brasil confirmou o primeiro caso da doença em 23 de janeiro de 2020. A primeira morte ocasionada pelo vírus aconteceu em 17 de março de 2020, segundo o órgão. Com aproximadamente seis milhões de casos confirmados e trezentos e oitenta mil mortes, as projeções seguem em crescimento, o que agrava a situação e impacta o andamento econômico, político, social, cultural e de pesquisas em diversos âmbitos, fazendo com que uma corrida potencial a vacina para a doença seja uma preocupação de todos os países do velho ao novíssimo mundo.

Em contexto atual, a Organização Pan-Americana da Saúde (OPAS) tem auxiliado e ofertado ferramentas que facilitem potenciais tomadas de decisões dos governos, tanto do ponto de vista farmacológico, bem como de medidas restritivas ao isolamento social, com o objetivo de redução de danos e prevenção a transmissão do vírus pela população mundial, com foco na minimização do caráter agressivo epidemiológico.

Assim, a partir deste cenário de tempos críticos, percebe-se a difusão de conhecimentos e informações relacionadas a Pandemia. É nesta celeuma que questões verdadeiras e falsas acabam por surgir e, de maneira atenuante, o processo comunicacional acaba influindo em aspectos fundamentais de comportamento dos indivíduos.

A ampliação da conexão via internet e das múltiplas mídias/redes sociais, tem possibilitado que novas ferramentas tecnológicas levem estudos e experiências a qualquer hora e em qualquer lugar para um número significativo de sujeitos. Com efeito, todo esse conectivismo "surge num momento em que a produção e a circulação das informações na internet são multiplicadas exponencialmente". (PIMENTEL, 2018, p. 126).

Isto posto, pensando em aspectos informacionais e comunicacionais, destaca-se a proliferação de fake News como um dos ciclos fenomenológicos dos pós - verdade, instaurando-se pela desconfiança e desinformação, muitas vezes alimentada pela mídia como dispositivo de controle do conhecimento. Para Santaella (2018, p. 33), "quando a confusão e a falta de confiança nas fontes se instalam, as portas ficam abertas para que a desinformação tome o comando", como acontece em relação ao que é disponibilizado sobre a COVID-19, 
artes de

educar

ressonando no pânico social, paranoias coletivas e embates políticos.

Neste cenário, no Brasil, são colocadas em voga algumas notícias de caráter inverídico, principalmente com relação ao tratamento relacionado ao Coronavírus. Um exemplo disto, é a (hidroxi)cloriquina que foi usada em muitas partes do país, contudo, após pesquisas e estudos científicos oficiais sobre a medicação, as prescrições estão sendo suspensas. A Organização Mundial de Saúde se manteve contra as recomendações, o que causou instabilidade na política brasileira e afetou, significativamente, a população infectada pelo vírus.

Doravante, este escrito tem por objetivo analisar a incidência das fake news em tempos de pandemia no Brasil, assim como processo de desinformação e discursos de ódio nas redes sociais, tomando como exemplo a discussão da medicação (hidroxi)cloriquina no tratamento de pacientes infectados pela COVID-19. Para tal, busca-se investigar e apontar perspectivas relativas ao negacionismo científico e o uso estratégico da medicação como manipulação e jogos de interesses do governo atual nos conhecimentos difundidos entre a população brasileira, e, por fim, propor alternativas de caráter educativo para combater essas fake news em âmbito brasileiro no contexto da COVID-19.

O texto será dividido em 4 sessões teóricas. Na sessão "Fake News e a Pandemia da COVID-19", uma discussão sobre a conceituação e a historicidade das fake news será apresentada, bem como será feita uma analogia acerca do fenômeno das notícias falsas com a pandemia da COVID-19, e de que forma as fake News vem contribuindo no processo de desinformação da sociedade em tempos de pandemia.

Na sessão "Negacionismo Científico e a Pandemia da COVID-19", uma discussão sobre a multiplicação de informações em Redes e o "anti-intelectualismo" serão bases de diálogo do espaço, com vistas a tessituras conceituais, identificando o cenário contemporâneo que é favorável ao negacionismo científico.

Na sessão "Discursos de Ódio Como Ressonância da Desinformação:”, tem-se a apresentação dos discursos de ódio presentes nas redes sociais como ressonância da desinformação fomentada pelo fenômeno das fake news. É importante salientar que não podese generalizar que toda e qualquer fake news e a desinformação ressoam em discursos de ódio; mas, nesta sessão, apresentamos uma análise, onde identificamos manifestações odiosas por parte de usuários da rede internet em uma publicação do jornal "Folha de S. Paulo" em seu perfil no Twitter.

Na sessão "Medidas Educativas para Enfrentamento as Fake News", apresentarse-á medidas que as instituições de ensino e seus educadores podem mediar com seus 


\section{artes de}

educar

discentes a fim de auxiliá-los na checagem das notícias falsas, para frear a proliferação das mesmas. Destarte, esta pesquisa procura fitar diálogos que contribuam com questões democráticas no Brasil em tempos de Pandemia, a fim de refletir saberes e fazeres transformadores e combativos em um contexto de incertezas e inverdades produzidas constantemente com o intuito de alcançar manobras políticas e interesses de uma classe dominante que não agrega valores ao desenvolvimento responsável da democracia brasileira.

\section{PERCURSOS DE PESQUISA: CAMINHOS METODOLÓGICOS PARA ANÁliSE DE EVIDÊNCIAS NA REDE}

Com a ideia de deslindar indagações referentes ao que é disponibilizado nas redes enquanto perigo ao processo informacional da sociedade brasileira, surge o seguinte problema de pesquisa: De que forma as fake news possibilitam os discursos de ódio em redes sociais, potencializando a desinformação e constituindo um cenário antidemocrático no Brasil em tempos de pandemia?

A abordagem metodológica é a netnografia, também conhecida como Etnografia Virtual (HINE, 2004), se constitui ideal para esse estudo, tendo em vista que é uma metodologia que considera interrelações em espaço híbrido por meio de tecnologias diversas, de maneira que "uma etnografia da Internet pode observar em detalhes as maneiras em que nós experimentamos a utilização de uma tecnologia (HINE, 2004, p. 13)”.

Além disso, tem-se a revisão de literatura que vem com o objetivo de comprovar e argumentar com a máxima profundidade as perspectivas levantadas, assumindo um rigor indispensável ao objetivo que se deseja alcançar, pois "pode ser um tanto ingênuo pensar-se que ainda existam novos campos a serem explorados e sobre os quais nada tenha sido publicado anteriormente (FLICK, 2009, p. 61).

Por fim, assume-se a abordagem desta pesquisa como qualitativa, tendo em vista a quantidade de variáveis sociais que serão analisadas, já que "a pesquisa qualitativa é de particular relevância ao estudo das relações sociais devido a pluralização das esferas de vida (FLICK, 2009, p. 20).

\section{FAKE NEWS E A PANDEMIA DA COVID-19}

Para iniciar o debate acerca do fenômeno das chamadas fake news como conhecemos e lidamos na cotidianidade, faz-se necessário entendermos o meio em que elas ganharam força. Isto é, criação e proliferação de notícias falsas já existiam na "era pré-redes" 
educar

(SANTAELLA, 2018, p. 7); todavia, com o desenvolvimento das tecnologias digitais e a propalação da internet, as fake news ressurgiram com características mais sofisticadas, amparadas pelos atuais processos comunicacionais.

Pesquisadores no que concerne os hábitos de navegação e comunicação em rede entendem que "as aplicações tecnológicas apresentam drásticos desvios do uso originalmente esperado. São, de fato, os usuários que criam novos domínios de aplicação e funcionalidades pela descoberta e criação de necessidades e práticas insuspeitadas" (SANTAELLA, 2010, p. 172). Na sua afirmação, Santaella (2010) assinala que os sujeitos sociais ativos na rede internet a manipulam com intencionalidades diversas, as quais, por vezes, apontam para a criminalidade.

Faz-se necessário acentuar também que, segundo a Pesquisa Nacional por Amostra de Domicílios Contínua 2018 (PNAD contínua TIC), 181,9 milhões de brasileiros se conectaram a internet, o equivalente a $69,8 \%$ da população com idade acima de 10 anos; desses, 99,2\% dos brasileiros utilizaram o dispositivo móvel (smartphone) para se conectar a rede. Além disso, a pesquisa também revelou que a principal atividade dos sujeitos conectados a internet é a troca de mensagens (áudio, texto ou imagens) através de aplicativos diferentes de e-mail.

Nesse ínterim, Santaella (2018, p. 20) afirma que as fake news costumam ser definidas como "[...] notícias, estórias, boatos, fofocas ou rumores que são deliberadamente criados para ludibriar ou fornecer informações enganadoras. Elas visam influenciar as crenças das pessoas, manipulá-las politicamente ou causar confusões em prol de interesses escusos. Consoante ela, Gomes; Dourado (2019, p.35) dizem ser “[...] relatos pretensamente factuais que inventam ou alteram os fatos que narram e que são disseminados, em larga escala, nas mídias sociais, por pessoas interessadas nos efeitos que eles poderiam produzir”.

O professor Wilson Gomes, em sua participação na Mesa "Democracia e política na plataforma digital: o desafio das fake News", no Congresso Virtual da Universidade Federal da Bahia (UFBA) 2020, afirmou, em sua fala, que para entendermos as atuais configurações no que se refere as fake news, necessita-se de uma análise através de quatro questionamentos basilares: 1. O que são as fake news? 2. Quais os meios de divulgação? 3. Qual a intencionalidade? 4. Quais as consequências?

No tocante ao conceito de fake news, Gomes diz que estas são informações, relatos sobre fatos ou descrição de fatos, mesmo sendo falsos, pois é desta forma que chega para os destinatários. $\mathrm{O}$ autor frisa que estas existiam em todas as sociedades dos séculos passados, mas se tornaram um tipo peculiar, por ser distribuído e consumido digitalmente. 
Com relação a divulgação e difusão, Gomes afirma que o principal meio utilizado é o digital, principalmente no que corresponde a guerrilha informacional para a política suja, além das mudanças culturais nos processos comunicacionais.

A respeito da intencionalidade, o professor alega que as fake news são produzidas como ferramentas para conseguir um determinado efeito, em geral, político. Elas intentam enganar e influenciar o comportamento das pessoas, produzir e destruir imagem e reputação de pessoas ou instituições e disseminar convicções favoráveis de quem a produziu.

No que concerne as consequências, Gomes abona que estas são variadas, e têm efeitos que refletem nos aspectos sociais, econômica e sanitários, além das consequências antidemocráticas - como a perturbação do sistema eleitoreiro, com a finalidade de minar a credibilidade do processo eleitoral.

Nessa contextura, a pandemia do novo coronavírus (Sars-Cov-2) trouxe consigo um estopim de fake news, o que acarretou numa infodemia - termo utilizado pela OMS para definir o excesso de informações, algumas precisas e outras não, que tornam difícil encontrar fontes e orientações confiáveis, atrapalhando o entendimento da sociedade acerca da doença. Os fatos noticiosos perpassam por dados não oficiais de infectados e mortos, estudos de medicamentos que devem ou não ser utilizados no combate e prevenção da COVID-19 e teorias da conspiração associadas a discursos religiosos que vendem supostas fórmulas médicas para cura da doença; sucedendo no processo de desinformação.

Sobre a desinformação, depreende-se que são informações falsas ou imprecisas, que possuem a intencionalidade de enganar. No contexto da pandemia atual, pode afetar profundamente todos os aspectos de prevenção a doença, pois a busca por atualizações sobre a COVID-19 na Internet - principal ambiente de disseminação de fake news - é uma crescente. Para além, desinformação pode circular e ser absorvida muito rapidamente, mudando o comportamento dos sujeitos, levando-os a correr riscos maiores. Isso agrava a situação da pandemia, na medida em que afeta mais pessoas, comprometendo a sustentabilidade do sistema de saúde.

Segundo Gomes (2020), campanhas de desinformação começaram a ser difundidas desde a Primeira Guerra Mundial, sendo, portanto, um termo bélico. A intencionalidade delas eram fazer chegar aos inimigos informações distorcidas, com fatos ou dados modificados, com o objetivo de engana-los. Para ele, as fake news são um meio de promover a desinformação; sendo esta, uma consequência das notícias falsas.

Um estudo realizado pelo Centro de Análise da Liberdade e do Autoritarismo (Laut), o Centro de Estudos e Pesquisas de Direito Sanitário (Cepedisa), e o Instituto Nacional de 
artes de

educar

Ciência e Tecnologia em Democracia Digital (INCT.DD) sediado na UFBA, constatou que canais que divulgam fake news sobre o novo coronavírus têm três vezes mais no YouTube do que os trabalham com informações legítimas.

Nessa perspectiva, entende-se que a infodemia é uma consequência das fake news, resultando no processo de desinformação para a sociedade, no tempo em que dificulta que informações verídicas e importantes sejam acessadas pelos indivíduos de modo geral. Para mais, essa desinformação é agravada quando se compreende que as pessoas preferem consumir fake news - por estas apresentarem um ponto de vista que ratifique seus pensamentos e preferências - a acreditarem em fontes confiáveis e até mesmo em estudos científicos. Para Gomes (2020), a vontade dos sujeitos em ter razão sobre determinados assuntos vem tornando-se mais importante do que informar-se veridicamente.

De mais a mais, é importante frisar-se também que o atual presidente da república, Jair M. Bolsonaro, tem contribuído para a desinformação em tempos de pandemia mundial. $\mathrm{O}$ líder do poder executivo, por vezes, desacredita e nega os estudos científicos acerca da prevenção e tratamento da COVID-19 e veicula informações contrárias as recomendações da OMS - como o isolamento e distanciamento social - e de instituições científicas brasileiras, a exemplo da Fundação Oswaldo Cruz (Fiocruz).

Desde o início da quarentena no Brasil, Bolsonaro - em suas redes sociais e pronunciamentos televisionados - defende o uso das medicações cloroquina e hidroxicloroquina para tratamento do novo coronavírus. Além disso, o presidente, em sua conta na rede social twitter, se posicionou contra o isolamento social e teve seu post apagado pela plataforma. O twitter afirmou que o post foi apagado, porque violava as novas regras da rede social com o objetivo de combater informações e conteúdos que vão de encontro com as orientações de saúde pública oriundas de instituições e organizações oficiais e possam colocar as pessoas em maior risco de transmitir o COVID-19. Após o Twitter, o Facebook e o Instagram seguiram o mesmo exemplo. $\mathrm{O}$ fato foi noticiado pela grande mídia brasileira, como o portal de notícias G1 e o Jornal Folha de S. Paulo.

Em relação a Cloroquina, a medicação gerou discordância entre dois ex-ministros da Saúde e o presidente Jair Bolsonaro. Tanto Luiz Henrique Mandetta quanto Nelson Teich, ambos médicos, alertaram para os efeitos colaterais dos remédios, mas, mesmo assim, Bolsonaro defendeu o uso deles contra a COVID-19. O Brasil, até o momento que vos escrevo, segue sem Ministro da Saúde, e o Ministério tem sido liderado por um ministro interino, Eduardo Pazuello, general de divisão do Exército Brasileiro, sem formação médica. 
No dia 20 de maio, o Ministério da Saúde divulgou um documento que traz um protocolo para aplicação da cloroquina e hidroxicloroquina em pacientes em todos os casos, inclusive os com sintomas leves, para tratar do novo coronavírus. O protocolo, que sugere a combinação dos dois medicamentos com Azitromicina, é uma orientação para a rede pública de saúde. Dois dias depois, a renomada revista inglesa dedicada a medicina, The Lancet, divulgou um estudo robusto apontando que a cloroquina e a hidroxicloroquina não apresentam melhora na recuperação de pacientes com COVID-19em uma base de 96 mil infectados, existindo, ainda, um risco maior de morte e piora cardíaca durante a hospitalização. A pesquisa levou a OMS a suspender o uso da cloroquina e hidroxicloroquina em pesquisas que ela coordenava com cientistas de 100 países. No Brasil, o Ministério da Saúde segue com seu protocolo para o uso dos medicamentos na saúde pública.

Entretanto, no dia 03 de junho, duas semanas após divulgação do estudo, três dos quatro autores do artigo publicado na revista "The Lancet" publicaram uma retratação, após os dados que usaram no trabalho terem sido questionados. $\mathrm{O}$ estudo foi retirado da rede pelos autores e o diretor-geral da OMS, Tedros Adhanom Ghebreyesus, afirmou, em um pronunciamento oficial na mesma data, que a Organização retomaria os estudos acerca da medicação, porém continuaria não recomendando o uso do remédio para o tratamento da COVID-19 enquanto não obtiverem dados científicos que comprovem sua eficácia. Duas semanas depois, a OMS voltou a suspender os estudos da organização com o medicamento, pela falta de evidências da eficácia da droga.

No dia 07 de junho de 2020, o Ministério da Saúde divulgou dados divergentes sobre o número de novos casos e óbitos registrados nas últimas 24 horas. Em um primeiro momento, a pasta anunciou 1.382 mortes por COVID-19 no país, mas mais tarde alterou o número para 525, uma diferença de 857 . Houve ainda uma mudança no número de infectados. O primeiro balanço divulgado pelo ministério informava um total de 12.581 novos casos, contra 18.912 casos atuais. A mudança ocorreu entre as $20 \mathrm{~h} 37$, quando o balanço diário foi enviado à imprensa, e as 21h50, quando o site oficial foi atualizado.

Inconsistências na comunicação da evolução da pandemia no país marcaram o início do mês de junho (2020), que começou com atrasos de três horas na divulgação de balanço diário e culminou com a exclusão de dados históricos, consolidados e detalhamentos importantes para o entendimento de como a doença se comporta e para a análise da resposta do governo. Após diversas críticas de especialistas, pesquisadores e autoridades, a pasta voltou a divulgar o número consolidado das estatísticas, e anunciou que trará uma nova plataforma, até então em desenvolvimento, com informações referentes ao Brasil, aos estados, 


\section{artes de}

educar

às capitais e às regiões metropolitanas, contendo os respectivos gráficos de evolução diária dos novos registros. O presidente Jair Bolsonaro foi questionado por jornalistas sobre os atrasos na divulgação de dados sobre a pandemia do novo coronavírus, ao que respondeu "Acabou matéria do Jornal Nacional", fazendo referência ao jornal da Rede Globo de Televisão.

Com a finalidade de divulgar dados mais precisos acerca do avanço da pandemia no Brasil depois das inconsistências descritas acima, os veículos de comunicação G1, O Globo, Extra, O Estado de S.Paulo, Folha de S.Paulo e UOL decidiram formar uma parceria e trabalhar de forma colaborativa para buscar as informações necessárias nos 26 estados e no Distrito Federal.

Nessa iniciativa inédita, equipes de todos os veículos vão dividir tarefas e compartilhar as informações obtidas para que os brasileiros possam saber como está a evolução e o total de óbitos provocados pela COVID-19, além dos números consolidados de casos testados e com resultado positivo para o novo coronavírus. $\mathrm{O}$ balanço diário será fechado às $20 \mathrm{~h}$.

No dia 11 de junho de 2020, em suas redes sociais, Bolsonaro pediu que seus seguidores entrem e filmem o interior dos hospitais públicos e de campanha para averiguar se os leitos estão livres ou ocupados e, caso as imagens demonstrassem alguma irregularidade, que fossem enviadas ao governo federal. A entrada em unidades de saúde sem autorização é crime, pois viola o direito a privacidade dos pacientes, como prevê o art. $5^{\circ}$, inciso $\mathrm{X}$, da Constituição Federal de 1988, quando diz que "são invioláveis a intimidade, a vida privada, a honra e a imagem das pessoas, assegurado o direito a indenização pelo dano material ou moral decorrente de sua violação". Além disso, o ato põe o visitante/invasor em risco de contaminação do novo coronavírus e demais doenças infectocontagiosas podendo, assim, agravar a pandemia da COVID-19 e, consequentemente, um possível colapso no sistema de saúde brasileiro.

Os fatos discorridos alhures são exemplos de como o poder executivo tem contribuído para a desinformação, agindo negativamente no enfrentamento da pandemia. Ademais, veremos como esta desinformação gerou discursos de ódio nas redes sociais.

\section{NEGACIONAIMSO CIENTÍFICO E A PANDEMIA DO COVID-19}

A ideia de que o negacionismo em si é proveniente da palavra negação, esta considerada por Abbagnano (2007, p. 709) como "ato de contestação (recusa, repúdio, verneigung) de uma representação ou ideia”. É neste aspecto que se chama a atenção para 
aquilo que é veiculado nas mídias negando os avanços científicos e causando um sentimento de desequilíbrio, o que é natural, tendo em vista a conjuntura atual do mundo globalizado. Essa negação, ou pior, a difusão de informações falsas sobre as possíveis descobertas científicas em relação ao COVID-19, acaba por incidir em aspectos mentais nos sujeitos e avançar diálogos sobre os interesses políticos no país e pontos relativos a democracia.

Para tal, alerta-se para a ciência e sua presencialidade no tempo da pós verdade (SANTAELLA, 2018). Na verdade, o conhecimento científico passa por diversas transformações desde que seu papel ficou definido na sociedade e "dirigido à totalidade das coisas, essencialmente distinto do conhecimento das ciências particulares, que vai ao encontro de domínios parciais da realidade [...]" (HESSEN, 2000, p. 10-12).

Nesta direção, é por parte do conhecimento científico que as demandas técnicas estabilidade cotidiana operam e o mesmo acaba por uma reflexão sobre suas particularidades da vida humana, visto que possibilita enxergar, de modo metalinguístico, seus propósitos, a partir do fazer pensar no próprio "comportamento teórico, sobre aquilo que chamamos de Ciência [...]" (HESSEN, 2000, p. 10-12), produzindo o que chamamos de Teoria da Ciência, ou Teoria do conhecimento científico (HESSEN, 2000).

Com efeito, na sociedade brasileira, a negação da ciência vem se apresentando de diversas formas. Uma delas, por exemplo, é que, conectados em rede, os sujeitos se posicionam sobre aspectos relacionados a estudos científicos sobre a pandemia e, por diversas vezes, acusam as organizações científicas que apresentam pesquisas sobre a proliferação do vírus no país de "empresas comunistas". Para tal, os sujeitos se aportam em comentários evasivos, sem nenhuma base epistemológica e científica, o que acaba reafirmando a instauração do negacionismo científico no panorama político brasileiro.

A comprovação científica, atualmente, vem sendo colocada em questionamento, à medida que a descrença toma o lugar de destaque, em detrimento da comprovação por meio da ciência. Isso tem se dado pelo apoio de alguns governos a política anticientífica: rompimento de acordos, redução de incentivos à produção acadêmica, alteração de processos seletivos e a tentativa de interferências nos currículos pedagógicos, tem sido rotineiro tanto em âmbito brasileiro, quanto mundialmente. Como exemplo disto, pode-se destacar o governo dos Estados Unidos da América em várias sucessões de ações e mecânicas que acabam por impulsionar o ceticismo e a falta de interesse naquilo que é produzido com base na produção, construção e difusão do conhecimento.

Esses aspectos são sintomáticos em sociedade. Nesta contextura, em tempos críticos de Pandemia, ciência e política parecem seguir caminhos opostos, por diversas vezes, e por 
uma parcela da sociedade brasileira. Isso acaba fazendo com que o fenômeno da pós verdade, em sua essência fenomenológica, cause e produza efeito sobre as informações compartilhadas, instaure a veiculação de fake news e fomente a cultura da descredibilidade da ciência. O que de fato acontece é o sentimento de que, estamos vivendo uma teoria da conspiração política e isso, acarreta movimentos nocivos a informações verídicas.

\section{DISCURSOS DE ÓDIO COMO RESSONÂNCIA DA DESINFORMAÇÃO}

No dia 07 de abril do ano em curso, o jornal Folha de S. Paulo divulgou uma matéria, na qual revelava que a taxa de mortes com cloroquina equivale à de quem não usa, segundo estudo preliminar da Fiocruz. De 81 pacientes que usaram, 13\% foram a óbito, percentual parecido com o de estudos em que a droga não foi aplicada.

A notícia gerou diversas reações dos usuários das redes sociais, que comentaram e compartilharam a matéria com mensagens ofensivas e xingamentos ao jornal e a jornalista responsável pelo texto, tentativas de tirar a credibilidade do veículo de comunicação, além do negacionismo científico acerca do estudo da Fiocruz. Selecionamos alguns comentários na divulgação da notícia no Twitter na Folha de S. Paulo para discutir neste escrito.

\section{Imagem 1 - Acusações dos usuários da rede à Folha de S. Paulo}

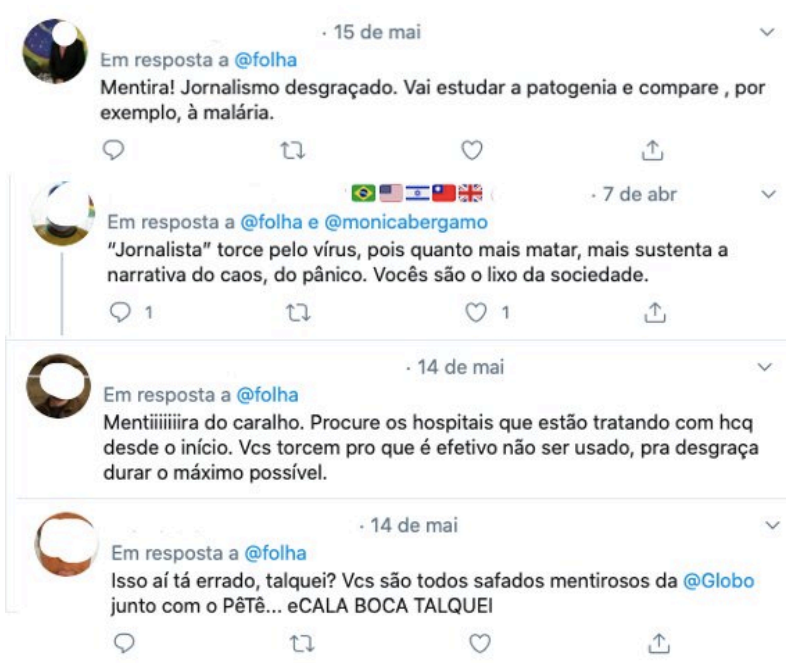

Fonte: Jornal Folha de S. Paulo, página no Twitter. Disponível em: https://twitter.com/folha?s=20 Acesso em: 18 jun. 2020.

Nos comentários acima, os usuários da rede proferem acusações para o veículo de comunicação em questão, dizendo que este é mentiroso, que torce pelo vírus para ter pautas a noticiar, que são desgraçados e safados filiados ao Partido dos Trabalhadores (PT) e a Rede 


\section{artes de}

educar

Globo de Televisão. Torna-se evidente, então, a tentativa de descredibilizar o jornalismo, que apenas noticiou um estudo de uma importante e reconhecida entidade científica nacional. Refletindo sobre a nossa presente sociedade, entende-se que o jornalismo está sim enfrentando uma crise no que tange a sua credibilidade devido ao fenômeno das fake news. Essa problemática também trouxe à tona o revés do papel político/social dos jornalistas.

É pertinente evidenciar também que os pesquisadores do estudo da Fiocruz divulgado pela reportagem passaram a ser atacados nas redes sociais, nos Estados Unidos e no Brasil. Em solo brasileiro, além dos ataques a eles e às famílias, alguns pesquisadores tiveram dados pessoais expostos na internet. No dia 17 de abril de 2020, o deputado federal Eduardo Bolsonaro, filho do presidente Jair Bolsonaro, divulgou ataques aos pesquisadores na página dele numa rede social. O deputado também escreveu que "o estudo clínico realizado em Manaus para desqualificar a cloroquina causou 11 mortes após pacientes receberem doses muito fora do padrão. Este absurdo deve ser investigado imediatamente", e continuou dizendo que "os responsáveis são do PT. Mas que isso é pura coincidência", como consta no Portal de Notícias G1, numa reportagem do dia 17 de abril de 2020.

O conselho deliberativo da Fiocruz disse, em nota, que os ataques a pesquisadores nas redes sociais são inaceitáveis. A fundação declarou que apoia incondicionalmente seu corpo de pesquisadores, que estão absolutamente comprometidos com a ciência e com a busca de soluções para o enfrentamento dessa pandemia.

Por fim, constata-se que os comentários expostos na imagem 1 - que acusam a Folha de S. Paulo de mentirosa - podem ser enquadrados como crime de injúria, conforme prevê o Art. 40 do Código Penal - Decreto Lei 2848/40, "Injuriar alguém, ofendendo-lhe a dignidade ou o decoro: Pena - detenção, de um a seis meses, ou multa" (BRASIL, 1940).

\section{Imagem 2 - Ofensas dos usuários da rede à Folha de S. Paulo e a jornalista Mônica}

\section{Bergamo}




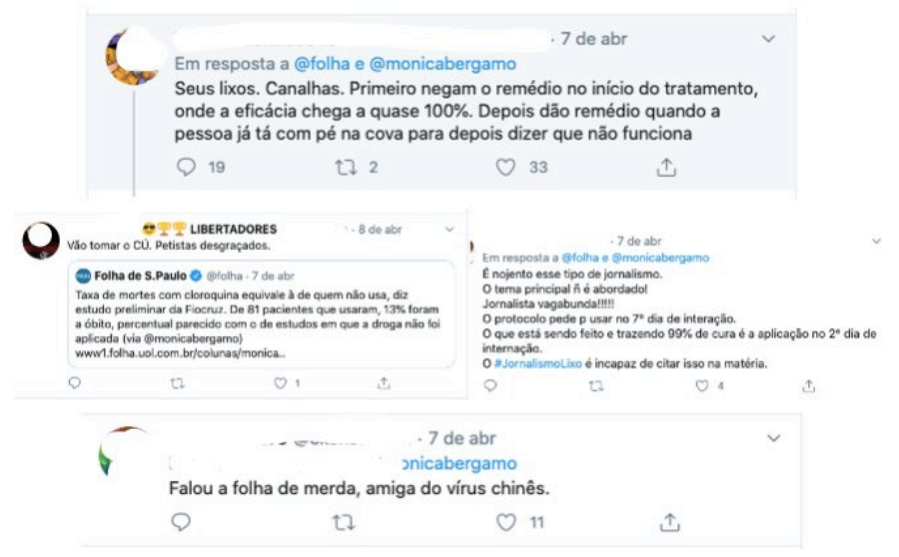

Fonte: Jornal Folha de S. Paulo, página no Twitter. Disponível em: https://twitter.com/folha?s=20 Acesso em: 18 jun. 2020.

Nos comentários da imagem dois, os usuários da rede proferem xingamentos ao veículo de comunicação em questão - Folha de S. Paulo - e a jornalista responsável pela reportagem, Mônica Bergamo, chamando-a de “Jornalista vagabunda!!!!!”, que podem ser caracterizados como discursos de ódio.

Consoante Butler apud Ribeiro (2018), “a linguagem opressora do discurso de ódio não é mera representação de uma ideia odiosa; ela é em si mesma uma conduta violenta, que visa submeter o outro, desconstruindo sua própria condição de sujeito, arrancando-o do seu contexto e colocando-o em outro onde paira a ameaça de uma violência real a ser cometida uma verdadeira ameaça, por certo”. (p. 781).

Sobre violência, Franco (1990) define como “[...] um processo dirigido a certos fins, tendo diferentes causas, assumindo formas variadas e produzindo certos danos, alterações e consequências imediatas ou a longo prazo". Essa definição nos permite pensar que a violência precisa ser interpretada e definida em suas várias faces, no mundo offline ou online, e por meio dos eventos em que se expressa, se repercute e se reproduz através da linguagem e do espaço em que é professado.

Rocha (2012), afirma que "[...] A possibilidade de anonimato na internet é o elemento que encoraja as atitudes agressivas” (p. 87). Consoante ela, Martino (2015) nos diz que “[...] o mundo virtual existe enquanto possibilidade, e se torna visível quando acessado, o que não significa que ele não seja real” (p. 31). Em outros termos, por oferecer a ilusão do suposto anonimato e por tornar-se um ambiente de rápida veiculação de mensagens com um grande alcance de público, esses crimes que já eram executados na vida off-line foram transferidos para a vida online. Destarte, os ativos digitais estão "[...] em constante encontro com a alteridade" (SANTOS, 2016, p. 54), e esse encontro tem se manifestado, por vezes, 
criminoso, odioso e violento dentro das redes sociais.

Todos os comentários presentes na imagem dois podem ser enquadrados como crime de injúria. A legislação está descrita no Art. 40 do Código Penal - Decreto Lei 2848/40, que diz, "Injuriar alguém, ofendendo-lhe a dignidade ou o decoro: Pena - detenção, de um a seis meses, ou multa”. (BRASIL, 1940).

\section{Imagem 3 - Usuários da rede questionam estudo científico}

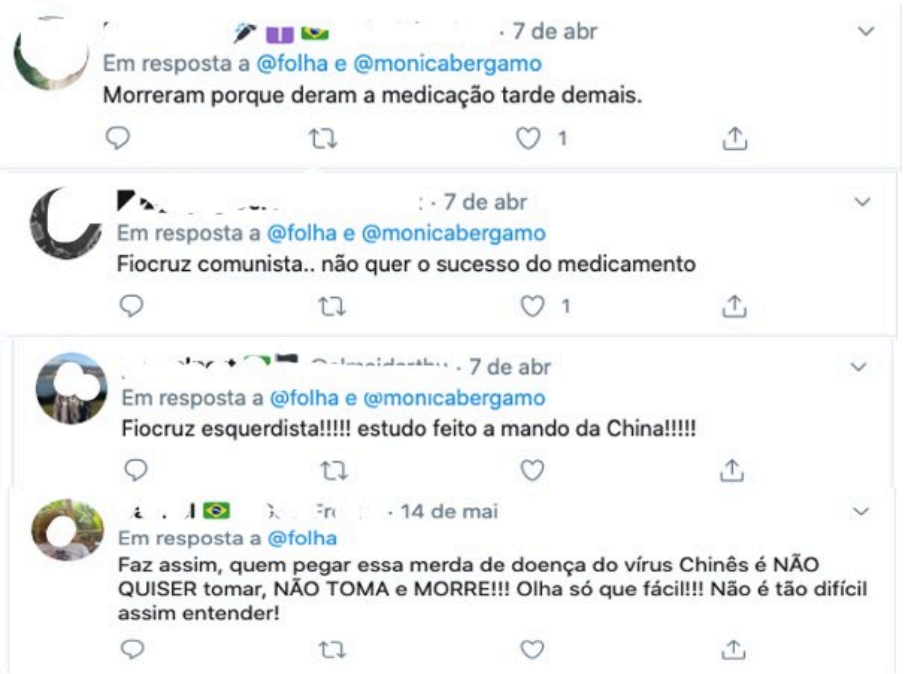

Fonte: Jornal Folha de S. Paulo, página no Twitter. Disponível em: https://twitter.com/folha?s=20 Acesso em: 18 jun. 2020.

Nos comentários da imagem três, os usuários da rede questionam o resultado do estudo científico sem a apresentação de qualquer argumento que fundamentem tais questionamentos, além de acusarem a Fiocruz de ser "comunista", "esquerdista" e que "não quer o sucesso do medicamento". Esses comentários também se caracterizam como negacionistas acerca do conhecimento e estudo científico.

A descrença com o conhecimento científico vem sendo tratado por alguns setores do governo e da sociedade. Até pouco tempo atrás, quando queríamos sustentar uma afirmação sem argumentar demais, bastava dizer: "É comprovado cientificamente.” Mas essa tática já não tem mais a mesma eficácia, pois a confiança na ciência está diminuindo. Vivemos hoje um clima de ceticismo generalizado, uma descrença nas instituições que favorece a disseminação de negacionismos, encampados por governos com políticas escancaradamente anticientíficas. É o caso de Jair Bolsonaro, que em 2019 mostrou-se contrário às ações para combater a mudança climática, por exemplo.

O fenômeno da pós-verdade - esse momento que atravessamos no qual fatos objetivos têm menos influência na opinião pública do que crenças pessoais - é um sintoma extremo 


\section{artes de}

educar

dessa crise. Os sujeitos sociais não enxergam que a ciência, assim como a política, existem para servir a sociedade. E sse desencanto produz um terreno fértil para movimentos anticiência e teorias da conspiração, além de fomentar fake news. O acesso facilitado, rápido e globalizado a informação, demasiadas vezes sem compromisso com a veracidade de fatos, criam negacionismo e desconfianças da sociedade no que concerne às instituições democráticas e o conhecimento científico. Em situações em que as fake news são consumidas, compartilhadas e mais legitimadas do que a verdade, instauram-se crises de valores e polarizações políticas. A pós-verdade, assim, não designa apenas o uso oportunista da mentira. O termo sinaliza, acima de tudo, um ceticismo quanto aos benefícios das verdades que costumavam compor um repertório comum, o que explica certo desprezo por evidências factuais usadas na argumentação científica. Evidências e consensos científicos têm sido contestados com base em convicções pessoais ou experiências vividas, como se percebe nos comentários na imagem 3, apresentada anteriormente.

Nessa contextura, valida-se entender que,

O prefixo pós significa não só depois de um evento ou situação específica (como pós-guerra), mas corresponde a um tempo em que um conceito se tornou sem valor ou justificação (como pós-moderno e pós-digital). A arte das mentiras esconde ou camufla as verdadeiras dimensões da realidade. Para Arendt (2005), a verdade fatual está sempre correndo o risco de ser distorcida por mentiras organizadas de grupos, países ou classes. (HABOWSKI; CONTE; BRADT, 2020, p. 494)

Nesse sentido, a discussão sobre pós-verdade necessita emergir nesta sociedade que se inscreve em meio a vida das pessoas, de modo que a interação permitida pelo uso de dispositivos e as potencialidades das TIC tem contribuído para repensar as dinâmicas sociais e, nessa conformidade, refletir sobre suas implicações nos mecanismos e estratagemas de poder.

Ao redor do mundo, as pessoas vêm manifestando uma confiança apenas moderada na ciência, mesmo nas nações mais ricas. Nos países com renda de média para alta - grupo em que o Brasil se enquadra -, 54\% dos habitantes confiam medianamente na ciência. $\mathrm{O}$ resultado foi obtido pelo Wellcome Global Monitor, um levantamento britânico de 2018 que investigou como a população de mais de 140 países se posiciona em relação a questões de ciência e saúde. O Centro de Gestão e Estudos Estratégicos (CGEE) por demanda do Ministério da Ciência, Tecnologia, Inovações e Comunicações (MCTIC), realizou um estudo acerca da Percepção pública da C\&T no Brasil 2019. Dentre os resultados, foi registrado uma redução na proporção dos que consideram os cientistas pessoas que fazem coisas úteis 
para a sociedade. Em 2010, esse número era de 55,5\% dos entrevistados, em 2015 caiu para $52 \%$ e, em 2019, para 41\%.

Os três primeiros comentários previstos na imagem três também podem ser enquadrados como crime de injúria. A legislação está dita alhures.

\section{MEDIDAS EDUCATIVAS PARA ENFRENTAMENTO AS FAKE NEWS}

A educação precisa compreender os fenômenos da cultura e de que maneira os processos de socialização são influenciados. Estudos nos indicam que as interações mediadas por computadores atuam nos modos de pensar e agir de todos nós. A este respeito, é bastante oportuno entendermos que as tecnologias, os softwares sociais na contemporaneidade têm tornado o ensino mais complexo e, com isso, criam desafios didáticos ao trabalho e papel docente.

Para compreendermos o papel da docência, devemos começar analisando seu sentido etimológico. Docência tem suas raízes no latim - docere - que significa ensinar, instruir, mostrar, indicar, dar a entender. No dicionário de língua portuguesa online, docência corresponde a ação ou resultado de ensinar; ato de exercer o magistério; ministrar aulas. Característica ou particularidade de docente.

Partindo para compreensão formal, docência é o trabalho dos professores, cujo seu desempenho articula um conjunto de saberes, que ultrapassam a tarefa de ministrar aulas, ter conhecimento sobre os componentes curriculares, métodos de ensino e instrumentos de avaliação.

Os desafios da profissão na contemporaneidade foram tornando-se mais complexos por conta da conjuntura político social do país. Por ou lado, estamos diante da ampliação do campo da docência na contemporaneidade, prevista na Lei No 9.394/96, como aponta o Art. $13^{\circ}$, que estabelece, além da elaboração da proposta pedagógica, do cumprimento do plano de trabalho e do desenvolvimento da aprendizagem dos alunos, a colaboração das atividades de articulação da escola com a família e as comunidades.

Ao tratar desses desafios, não podemos deixar de mencionar que o trabalho docente está ligado à inovação pedagógica e tecnológica; para isto, é preciso romper com o conservadorismo de pesquisar, ensinar, aprender e avaliar e, dar lugar a inventividade e criatividade conquistados pela sua capacidade de autonomia.

Em meio a complexidade contemporânea, alguns docentes ainda acreditam que seu papel é ensinar os conteúdos dos saberes específicos de sua disciplina, sem articular os 
artes de

educar

saberes da experiência dos discentes, apoiada em uma didática instrumental, aquela que não conecta a cultura e o cotidiano escolar em sua atitude de investigação.

Sendo a didática um campo que investiga os fundamentos, as condições e os modos de realizar a educação por meio do ensino, nesse contexto de fenômeno das fake news, docentes de diferentes áreas do conhecimento tem a função de tornar as informações do jornalismo profissional e artigos de divulgação científica, em conteúdos formativos de suas práticas cotidianas.

Isto é, as instituições de ensino, nesse momento de pandemia da COVID-19 e "epidemia" das fake news, precisam aliar-se ao jornalismo profissional, sério e de credibilidade para, com a ajuda deles, mediar conhecimentos com seus educandos acerca da atual situação do país e de como as notícias falsas vem atrapalhando no controle da pandemia, assim como no sistema democrático brasileiro.

Uma medida que pode ser utilizada como ferramenta para enfrentamento das fake news é mediar com os discentes os sites que a grande mídia brasileira e mundial tem criado para atuarem na checagem da fatos e notícias, além de serem um canal para denunciar fake news. Alguns desses sites forem supracitados na sessão anterior.

Outra medida que pode ser eficaz é mediar com os educandos noções básicas de como o jornalismo constrói uma notícia. Ou seja, regras como lide, por exemplo, - que consiste em fornecer ao leitor logo no primeiro parágrafo de uma matéria as informações mais importantes do fato ocorrido -, se forem do conhecimento dos discentes, podem ajudá-los na identificação das fake news. É importante frisar também que, se surgir qualquer dúvida a respeito da notícia, que esta seja sanada antes de compartilhar as informações com outrem e, principalmente, nas redes sociais.

Para mais, nesse cenário onde a educação passou a ser mediada pelas tecnologias digitais, os docentes podem utilizar as redes sociais como ambiente de aprendizado, já que a sociedade brasileira está imersa nessa contextura - como consta na Pnad 2018 dita alhures -, e sabendo que estas redes são o principal meio onde as fake news são difundidas.

Nesse cenário, todas as mídias, artefatos, unidades sonoras, impressas e disponíveis para acessibilidade, digitais, eletroeletrônicas etc., que facilitem o processo educativo e se liguem ao desempenho e aprendizagem, podem tornar-se uma tecnologia a serviço da educação (CRUZ, 2019), a depender do foco e objetivo, sendo, portanto, uma tecnologia educacional, assim como encaminha os estudos de Tajra (2001)

[...] a tecnologia educacional está relacionada aos antigos instrumentos utilizados no processo e ensino-aprendizagem. O giz, a lousa, o 
retroprojetor, o vídeo, a televisão, o jornal impresso, um aparelho de som, um gravador de fitas cassetes e de vídeo, o rádio, o livro e o computador são todos elementos instrumentais componentes da tecnologia educacional. (p. 48)

Nessa perspectiva, a educação mediada por tecnologias pode ser concebida por sua maneira de organizar, elaborar, sistematizar, avaliar e procedimentar o uso e a combinação de recursos e materiais tecnológicos no alcance de objetivos comuns aos processos de ensino e aprendizagem, na busca de transformação nos saberes e fazeres educativos, com foco e potencialização no processo comunicativo e inventivo de criação de meios e fins para a produção, construção e difusão do conhecimento.

Destarte, esse processo educacional com aporte tecnológico se efetiva nas práticas e na sua (res) significação para aprendizagem, em vários espaços educacionais. Todas as produções com essa finalidade no contexto educativo e incorporado à didática e metodologia de ensino é uma tecnologia aplicada (CRUZ, 2019), fazendo de professores e educandos criadores de subsídios que impulsionam a construção do conhecimento. Dessa maneira, vale o pensamento de que:

As instituições educacionais também produzem tecnologia (softwares, livros, vídeos, jornais). Essa produção não se limita apenas a novas invenções, mas, inclusive, a elaborar críticas sobre as produções tecnológicas, vinculados a tecnologia à didática e à cultura (TAJRA, 2001, p.46).

Nesse ínterim, as tecnologias possibilitaram inúmeras maneiras de disseminação de informações entre sujeitos de lugares e culturas diferentes, formando, assim, uma “inteligência coletiva" (JENKINS, 2008, p. 30).

Assim, valia-se ressaltar que estamos em ano de eleições presidências e, até o presente momento que vos escrevemos, estas não foram adiadas e, logo, as instituições de ensino podem e devem trabalhar para que as notícias falsas não interfiram no senso crítico dos educandos e das comunidades na escolha de seus representantes municipais para, dessa forma, fazer valer nosso sistema democrático e nossa democracia.

Por fim, lembremos que Anísio Teixeira afirmava que, "Democracias sem educação e educação sem liberdade são antinomias, em teorias, que desfecham, na prática, em fracassos inevitáveis" (TEIXEIRA, 2007, p. 59).

\section{CONCLUSÃO}


O Brasil detém o recorde mundial em peças de desinformação sobre o total de casos e mortes por COVID-19, doença causada pelo novo coronavírus, perdendo apenas para os EUA. Desde o início da pandemia até o dia 8 de junho, plataformas de checagem de fatos mundialmente produziram 34 verificações de peças de desinformação questionando esses dados, o que equivale a quase um quinto dos 149 conteúdos desse tipo analisados no período.

O Brasil também não aderiu a uma iniciativa de países de todo o mundo para estabelecer um compromisso de não difundir desinformação em meio à pandemia. $\mathrm{O}$ documento foi assinado por 132 países, como Israel, Índia, Hungria e Japão, Reino Unido, França, Itália, EUA, dentro outros. O documento, que elogia os trabalhos da Organização das Nações Unidas (ONU) e OMS nessa questão, ainda confirma que a imprensa livre é fundamental e deve ser independente, responsável e pluralista para aumentar a transparência, a responsabilidade e a confiança, o que é essencial para alcançar o apoio adequado e a conformidade do público em geral com os esforços coletivos para conter a propagação do vírus.

Além de dificultar o enfrentamento da pandemia da COVID-19, a desinformação ressoa em crimes e discursos de ódio na rede, outra problemática enfrentada pela sociedade brasileira, pois os crimes relacionados ao ódio, na esfera off-line e online, se transformaram numa questão estatal e sua repreensão reflete a preocupação quanto a influência deste fenômeno na vida social das coletividades.

O negacionismo científico também se evidenciou como ressonância da desinformação, o que nos leva a reflexão de como as universidades, sobretudo públicas, precisam, gradativamente, fomentar e defender os estudos científicos, com o propósito de ratificar a necessidade e a importância da ciência para a nossa nação e para o mundo.

Nesse sentido, é importante salientar que o desenvolvimento tecnológico digital e o acesso a internet não devem ser responsabilizados pelo mal que acontece no ciberespaço, pois, atrás de um dispositivo tecnológico digital tem um operador humano que manipula as interações.

Em setembro de 2019, a Câmara dos Deputados e o Senado Federal instauraram a Comissão Parlamentar Mista de Inquérito (CPMI) das Fake News, com o intuito de investigar a existência de uma rede de produção e propagação de desinformação, notícias falsas e assédio virtual na rede internet. O responsável pela instauração foi o Senador Ângelo Coronel (PSD-BA), e a relatora nomeada foi a Deputada Federal Lídice da Mata (PSB-BA). A motivação para criação da CPMI foi a suspeita do uso de fake news, durante as eleições de 2018. 
Hodiernamente, tramita na Câmara dos Deputados um Projeto de Lei (PL) $\mathrm{n}^{\mathrm{o}}$ 2630/2020, que estabelece normas relativas à transparência de redes sociais e serviços de mensagens privadas. Outrossim, o Supremo Tribunal Federal (STF) instaurou um inquérito (INQ) 4.781 com o objetivo de apurar notícias fraudulentas (fake news), denunciações caluniosas, ofensas e ameaças a ministros da Corte.

\section{REFERENCIAS}

ABBAGNANO, N. Dicionário de Filosofia. São Paulo: Martins Fontes, 2007.

BRASIL. Comissão Parlamentar Mista de Inquérito (CPMI); Investigar, no prazo de 180 dias, os ataques cibernéticos que atentam contra a democracia e o debate público. Relator (a) Lídice da Mata; em funcionamento, 2020.

BRASIL. Constituição federativa do Brasil de 1988. Diário Oficial [da] República Federativa do Brasil. Brasília, DF, 20 de dezembro de 1988.

BRASIL. Decreto-Lei 2.848, de 07 de dezembro de 1940. Código Penal. Diário Oficial da União, 2015.

BRASIL. Lei n. ${ }^{\circ} 9.394$, de 20 de dezembro de 1996. Estabelece as diretrizes e bases da educação nacional. Diário Oficial [da] República Federativa do Brasil. Brasília, DF, 20 de dezembro de 1996.

BRASIL. Ministério da Saúde divulga diretrizes para tratamento medicamentoso de pacientes. Mai. 2020. Distrito Federal: Ministério da Saúde do Brasil. Disponível em:https://www.saude.gov.br/noticias/agencia-saude/46919-ministerio-da-saude-divulgadiretrizes-para-tratamento-medicamentoso-de-pacientes. Acesso em: 18 de junho 2020.

BRASIL. Projeto de Lei no 2630 (Lei das Fake News); Institui a Lei Brasileira de Liberdade, Responsabilidade e Transparência na Internet. Relator Alessandro Vieira; em funcionamento, 2020.

BRASIL. Supremo Tribunal Federal. Inquérito (INQ) 4.781. Determinaram-se medidas investigatórias e de bloqueio à continuidade da divulgação de notícias fraudulentas (fake news). Relator Alexandre de Moraes. 26 de maio 2020.

BUTLER, J.; AGULAR, R. Problemas de Gênero: feminismo e subversão da identidade. São Paulo: Civilização Brasileira, 2018.

CHADE, Jamil. Brasil não adere ao compromisso de 130 países de lutar contra fake news. Jun. 2020. Disponível em https://noticias.uol.com.br/colunas/jamilchade/2020/06/16/brasil-nao-adere-ao-compromisso-de-130-paises-contra-fake-news-napandemia.htm. Acesso em: 18 de junho 2020. 
CRUZ, D. A. C. de S. e. Formação Continuada de Professores a Distância: Contribuições do Curso de Aperfeiçoamento em Tecnologias Educacionais na Prática Docente.

Dissertação (Mestrado Acadêmico). Departamento de Educação. Programa de Pós-Graduação em Educação e Contemporaneidade. Universidade do Estado da Bahia. Salvador/Bahia, 2019. 171 fls.

Democracia e política na plataforma digital: o desafio das fake News. Mesa redonda apresentada por Wilson Gomes, Lídice da Mata e Suzana Barbosa. [SSA, UFBA], 2020. 1 vídeo (1h 51min 24seg). Publicado pela Universidade Federal da Bahia. Disponível em https://www.youtube.com/watch?v=Pjp2ynQYU1s\&t=4801s. Acesso em 18 junho 2020.

FLICK, U. Introdução à Pesquisa Qualitativa. Tradução: Joice Elias Costa - 3. Ed. Porto Alegre. Porto Alegre: Artmed, 2009.

Folha de São Paulo (Folha S. Paulo). Taxa de mortes com cloroquina equivale à quem não usa, diz estudo preliminar da Fiocruz. De 81 pacientes que usaram, 13\% foram a óbito, percentual parecido com o de estudos em que a droga não foi aplicada (via (monicabergamo). 07 de abr. 2020, 11:30 AM. Tweet. Disponível em: https://twitter.com/folha/status/1247532179413823493. Acesso em: 18 de junho 2020.

FRANCO, S. La violência: un problema de salud pública que se agrava en la Región. Boletín Epidemiológico de la OPS, v.11, n. 2, p. 1-7, 1990.

Fundação Oswaldo Cruz (Fiocruz). Fiocruz divulga nota em defesa da ciência e de seus pesquisadores. Abr. 2020. Disponível em: https://portal.fiocruz.br/noticia/fiocruz-divulganota-em-defesa-da-ciencia-e-de-seus-pesquisadores. Acesso em: 18 de junho 2020.

GOMES, W. da S.; DOURADO, T. Fake news, um fenômeno de comunicação política entre jornalismo, política e democracia. Estudos em Jornalismo e Mídia. v. 16, nº 02, p. 33-45, jul./dez, 2019.

HABOWSKI, A. C.; CONTE, E.; BRADT, C. A Pós Verdade é Verdadeira ou Falsa? In: Educação Temática e Digital. Campinas, SP: 2020.

HESSEN, J. Teoria do Conhecimento. São Paulo: Martins Fontes, 2000

HINE, C. Etnografia virtual. Barcelona: UOC, 2004.

IBGE. PNAD Contínua TIC 2018: Internet chega a 79,1\% dos domicílios do país. Rio de Janeiro: abril de 2020. Disponível em: https://agenciadenoticias.ibge.gov.br/agencia-sala-deimprensa/2013-agencia-de-noticias/releases/27515-pnad-continua-tic-2018-internet-chega-a79-1-dos-domicilios-do-pais. Acesso em: 18 de junho 2020.

JENKINS, H. Cultura da Convergência. São Paulo: Aleph, 2008.

Jornal Folha de São Paulo. Bolsonaro estimula a população para filmar oferta de leitos. Jun. 2020. Disponível em: https://www1.folha.uol.com.br/cotidiano/2020/06/bolsonaro- 
estimula-populacao-a-invadir-hospitais-para-filmar-oferta-de-leitos.shtml. Acesso em: 18 de junho 2020.

Jornal Folha de São Paulo. Canais de Fake News sobre Covid - 19 no YouTube são vistos quase 3 vezes mais que os de dados reais. Jun. 2020. Disponível em:

https://www1.folha.uol.com.br/equilibrioesaude/2020/05/canais-de-fake-news-sobre-covid19-no-youtube-sao-vistos-quase-3-vezes-mais-que-os-de-dados-reais.shtml. Acesso em: $18 \mathrm{de}$ junho 2020.

Jornal Folha de São Paulo. Página do Twitter da folha. Disponível em: https://twitter.com/folha?s=20. Acesso em: 18 de junho 2020.

Jornal Folha de São Paulo. Taxa de mortes com cloroquina equivale à de quem não usa, diz estudo preliminar da Fiocruz. Jun. 2020. Disponível em: https://www1.folha.uol.com.br/colunas/monicabergamo/2020/04/taxa-de-mortes-comcloroquina-equivale-a-de-quem-nao-usa-diz-estudo-preliminar-da-fiocruz.shtml. Acesso em: 18 de junho 2020.

MACHADO, C. Caio; DOURADO, A. Daniel.; SANTOS, Nina.; SANTOS, Guilherme João. Ciência Contaminada. Rio de Janeiro: mai de 2020. Disponível em:

https://laut.org.br/cienciacontaminada.pdf?utm source $=$ twitter\&utm medium $=$ social\&utm campaign $=$ cincia contami nada. Acesso em: 18 de junho 2020.

MARQUES, J. Depois do Twitter, Facebook e Instagram também apagam post de Bolsonaro. Mar. 2020. São Paulo: Folha de São Paulo. Disponível em: https://www1.folha.uol.com.br/poder/2020/03/depois-do-twitter-facebook-tambem-apagapost-de-bolsonaro.shtml. Acesso em: 18 de junho 2020.

MARTINO, L. M. S. Teorias das Mídias Digitais. Linguagens, ambientes e redes. Petropólis: Vozes, 2015.

MATTA, A.; SILVA, F. P. S.; BOAVENTURA, E. Design-based research ou pesquisa de desenvolvimento: metodologia para pesquisa aplicada de inovação em educação no século XXI. In: Revista da Faeeba - Educação e Contemporaneidade. Salvador, vol. 23, n. 42, p.25 - 37 jul./dez, 2014.

MEHRA, R. Mandeep.; DESAI, S. Sapan.; RUSCHITZKA, Frank.; PATEL, N. Amit. Hydroxychloroquine or chloroquine with or without a macrolide for treatment of COVID-19: a multinational registry analysis. Mai. 2020. Disponível em:

https://www.thelancet.com/journals/lancet/article/PIIS0140-6736(20)31180-6/fulltext. Acesso em: 18 de junho 2020.

Organização Mundial da Saúde. Departamento de evidência e inteligência para ação em Saúde. Brasília: OMS; 2020. Disponível em:

https://iris.paho.org/bitstream/handle/10665.2/52054/FactsheetInfodemic por.pdf?sequence=3. Acesso em: 18 de junho 2020.

Organização Mundial da Saúde. Folha informativa - COVID - 19. Brasília: OMS; 2020. Disponível 
em: https://www.paho.org/bra/index.php?option=com_content\&view=featured\&Itemid=101. Acesso em: 18 de junho 2020.

Organização Mundial da Saúde. Folha informativa - COVID - 19. Brasília: OMS; 2020. Disponível

em: https://www.paho.org/bra/index.php?option=com_content\&view=article\&id=6105:novocoronavirus-fiocruz-ministerio-da-saude-do-brasil-e-opas-organizam-treinamento-emdiagnostico-laboratorial-para-9-paises\&Itemid=812. Acesso em: 18 de junho 2020.

Organização Mundial da Saúde. Folha informativa - COVID - 19. Brasília: OMS; 2020. Disponível

em: https://www.paho.org/bra/index.php?option=com content\&view=article\&id=6101:covid 19\&Itemid=875/. Acesso em: 18 de junho 2020.

Organização Mundial da Saúde. Folha informativa - COVID - 19. Brasília: OMS; 2020 [acesso em 13 de junho 2020]. Disponível em: Organização Mundial da Saúde. Folha informativa - COVID - 19. Brasília: OMS; 2020. Disponível

em: https://www.paho.org/bra/index.php?option=com_content\&view=article\&id=6101:covid 19\&Itemid=875. Acesso em: 18 de junho 2020.

Percepção pública da C\&T no Brasil - 2019. Resumo executivo. Brasília: Centro de Gestão e Estudos Estratégicos, 2019. Disponível em:

https://www.cgee.org.br/documents/10195/734063/CGEE_resumoexecutivo_Percepcao_pub CT.pdf. Acesso em: 18 de junho 2020.

PIMENTEL, C. S. F. Conectivismo. IN: BERTOLDO, H. L.; MILL, Daniel; SALTO, Francisco. Dicionário crítico de educação e Tecnologias e de Educação a Distância. MILL, Daniel (org.). Campinas, SP: Papirus, 2018.

Portal G1 de Notícias. “Acabou a matéria do Jornal Nacional, diz Bolsonaro sobre atrasos na divulgação de mortos por Corona Vírus. Jun. 2020. Disponível em: https://g1.globo.com/politica/noticia/2020/06/05/dados-do-coronavirus-bolsonaro-defendeexcluir-de-balanco-numero-de-mortos-de-dias-anteriores.ghtml. Acesso em: $18 \mathrm{de}$ junho 2020.

Portal G1 de Notícias. Estudo francês que recomendava hidroxicloroquina para tratamento de Covid-19 é retirado do ar. Mai. 2020. Disponível em: https://g1.globo.com/bemestar/coronavirus/noticia/2020/05/23/estudo-frances-querecomendava-hidroxicloroquina-para-tratamento-de-covid-19-e-retirado-do-ar.ghtml. Acesso em: 18 de junho 2020.

Portal G1 de notícias. Pesquisadores que testaram efeitos da cloriquina em pacientes da Covid-19 recebem ameaças. https://g1.globo.com/jornalnacional/noticia/2020/04/17/pesquisadores-que-testaram-efeitos-da-cloroquina-em-pacientesda-covid-19-recebem-ameacas.ghtml. Acesso em: 18 de junho 2020.

Portal G1 de Notícias. Twitter apaga publicações de Jair Bolsonaro por violarem regras da rede. Mar. 2020. Disponível em https://g1.globo.com/politica/noticia/2020/03/29/twitter- 
apaga-publicacoes-de-jair-bolsonaro-por-violarem-regras-da-rede.ghtml. Acesso em: 18 de junho 2020.

Portal G1 de Notícias. Veículos de Comunicação formam parceria para dar transparência a dados da COVID - 19. Jun. 2020. Disponível em:

https://g1.globo.com/politica/noticia/2020/06/08/veiculos-de-comunicacao-formam-parceriapara-dar-transparencia-a-dados-de-covid-19.ghtml. Acesso em: 18 de junho 2020.

Revista Eletrônica FAPESP. Resistência a Ciência. Disponível em: https://revistapesquisa.fapesp.br/resistencia-a-ciencia/. Acesso em: 18 de junho 2020.

RIBEIRO, D. Quem Tem Medo do Feminismo Negro?. São Paulo: Cia das Letras, 2018.

ROCHA, T. B. Cyberbullying: ódio, violência virtual e profissão docente. Brasília: Liber Livro, 2012.

ROQUE, Tatiana. O negocionismo no poder. Fev. 2020. Disponível em: https://piaui.folha.uol.com.br/materia/o-negacionismo-no-poder/. Acesso em: $18 \mathrm{de}$ junho 2020.

SANTAELLA, L. A pós-verdade é verdadeira ou falsa? São Paulo: Editora Estação das letras e cores, 2018.

SANTAELLA, L.; LEMOS, R.. Redes sociais digitais: a cognição conectiva do Twitter. São Paulo: Paulus, 2010.

SANTOS, M. A. M. Dos. O Discurso de Ódio nas Redes Sociais. São Paulo: Lura Editorial, 2016.

Site Aos Fatos. Com foco na Pandemia, aos fatos lança a robô checadora Fátima no WhatsApp. Rio de Janeiro: 2020. Disponível em: https://www.aosfatos.org/noticias/comfoco-na-pandemia-aos-fatos-lanca-robo-checadora-fatima-no-whatsapp/. Acesso em: 18 de junho 2020.

TARJA, S. F. Informática na Educação: novas ferramentas pedagógicas para o professor da atualidade. 3 ed. rev. e ampl. São Paulo: Érica, 2001.

TEIXEIRA, A. S. Educação Para Democracia: introdução à administração educacional. 3 ed. Rio de Janeiro: Editora UFRJ, 2007. 255p.

The Lancet Editors. Hydroxychloroquine or chloroquine with or without a macrolide for treatment of COVID-19: a multinational registry analysis. Jun. 2020. Disponível em: https://www.thelancet.com/journals/lanpub/article/PIIS0140-6736(20)31290-3/fulltext Acesso em: 18 de junho 2020.

Universidade Federal da Bahia. Rede Covida - Ciência, Informação e Solidariedade. Salvador: 2020. Disponível em: https://covid19br.org/sobre/. Acesso em: 18 de junho 2020.

Wellcome Global Monitor 2018. Disponível em: https://wellcome.ac.uk/reports/wellcomeglobal-monitor/2018. Acesso em: 18 de junho 2020. 


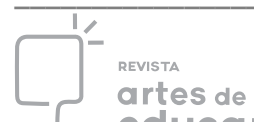

Word Health Organization. Corona Vírus desease (COVID-19) pandemic. Jun. 2020.

Disponível em: https://www.who.int/emergencies/diseases/novel-coronavirus-

2019? gclid=CjwKCAjw26H3BRB2EiwAy32zhSRuykdut-

h2uakERH9OHVJw7CF3e9YnysCRCT2LThIPsgagra6RpRoCPpsQAvD_BwE. Acesso em:

18 de junho 2020.

\footnotetext{
${ }^{\text {i }}$ Discente da Licenciatura em Pedagogia Universidade Federal da Bahia (UFBA), Bolsista PIBIC/CNPq. Salvador, Bahia, Brasil. E-mail: cleytonya26@gmail.com / ORCID: https://orcid.org/0000-0003-1047-0359

ii Mestre em Educação e Contemporaneidade pelo Programa de Pós-Graduação em Educação e Contemporaneidade da Universidade do Estado da Bahia. Salvador, Bahia, Brasil. E-mail: aric.diego1@gmail.com / ORCID: https://orcid.org/0000-0001-7124-0552

${ }^{\text {iii }}$ Doutora em Educação pela Universidade Federal da Bahia (UFBA). Professora de Didática da Faculdade de Educação (UFBA). Salvador, Bahia, Brasil. E-mail: telmabr@gmail.com / ORCID: https://orcid.org/0000-0002$\underline{8389-4542}$
} 